\title{
Association study of plasma NT-proBNP levels and severity of acute coronary syndrome
}

\author{
T. Tuxunguli, A. Aierken, X. Xie, C.F. Dai, Y.N. Yang, X.M. Li and \\ Y.T. Ma \\ Department of Cardiology, \\ First Affiliated Hospital of Xinjiang Medical University, Urumqi, China \\ Corresponding author: A. Aierken \\ E-mail: Aierkenaji@163.com
}

Genet. Mol. Res. 13 (3): 5754-5757 (2014)

Received May 28, 2013

Accepted October 1, 2013

Published July 29, 2014

DOI http://dx.doi.org/10.4238/2014.July.29.2

\begin{abstract}
The aim of this study was to investigate the N-terminal brain natriuretic peptide precursor (NT-proBNP) levels in the peripheral blood of patients with acute coronary syndrome (ACS) and to provide the basis for its application in the early diagnosis of ACS. A total of 440 patients admitted to the hospital for examination and treatment were enrolled, including 330 patients with ACS and 110 cases in the control group. Routine blood examination and determination of NT-proBNP in all subjects were conducted immediately at the time of admission to analyze the difference in plasma NT-proBNP between the two groups. The plasma NT-proBNP levels in ACS were significantly higher $(\mathrm{P}<$ 0.01 ) and were associated with the severity of coronary lesions. The present study indicated that the plasma NT-proBNP level in ACS patients is significantly increased and has a potential value in the early diagnosis of ACS.
\end{abstract}

Key words: Acute coronary syndrome; D-dimer; $\mathrm{N}$-terminal pro-brain natriuretic peptide precursor 


\section{INTRODUCTION}

Acute coronary syndrome (ACS) includes thrombosis formation and distal vascular thrombosis of various degrees after the rupture of coronary atherosclerotic plaque. It causes complete or incomplete block of the coronary artery, which presents the characteristics of acute onset, rapid progression, high severity and high mortality. The early diagnosis of ACS and opening of the blocked artery in reperfusion therapy are important factors affecting ACS prognosis (Gravning et al., 2013; Wlazel et al., 2013). Plasma NT-proBNP is one of the important indicators that reflect myocardial ischemia and cardiac function (Holm et al., 2013). In this study, plasma NT-proBNP level was determined in patients with ACS to investigate its potential value in the early diagnosis of ACS.

\section{MATERIAL AND METHODS}

\section{Clinical data}

A total of 440 patients who were examined and treated in our hospital from January 2012 to March 2013 were enrolled in this study, of which 332 were males and 108 females. A group of 330 patients were diagnosed with ACS and 110 patients were included in the control group. The patients selected had to meet the following conditions to be diagnosed with ACS. 1) Unstable angina pectoris, with the following conditions being met: (i) aggravated angina pectoris within 3 days with frequent onset and extended duration, with recent onset of angina lasting at least $15 \mathrm{~min}$; (ii) during the angina, transient ST segment depression $>1 \mathrm{~mm}$ or ST segment elevation $>3 \mathrm{~mm}$ in ECG, and after remission, ST segment changes returning to normal status or nearly normal status; (iii) last onset within $24 \mathrm{~h}$, with post-infarction angina being excluded. 2) Acute myocardial infarction which was based on clinical symptoms, ECG changes and dynamic evolution. Control group patients had stable angina pectoris (SAP) and chest pain history, but there was no positive finding on physical examination, electrocardiogram and stress test, echocardiography, and CAG checks. The patients with acute pulmonary embolism, myocarditis, peripheral vascular disease, stroke, severe liver and kidney disease, autoimmune diseases, blood diseases, inflammation, infection, severe systemic diseases and inflammation inhibitor history were excluded from this study.

\section{Specimen collection}

A 12-mL sample of venous blood was taken from all subjects immediately after admission and sent to clinical laboratory testing department in our hospital for assay of relevant indicators.

\section{NT-ProBNP detection}

An ELISA method was used and the specific procedure was carried out in strict accordance with the kit instructions.

\section{Statistical methods}

All the statistical analyses were performed with the statistical software SPSS 13.0. 
Results are reported as means \pm standard deviation (means $\pm \mathrm{SD}$ ), categorical data were compared with the chi-square test, and differences between groups were analyzed using one-way ANOVA. $\mathrm{P}<0.05$ was considered to be statistically significant.

\section{RESULTS}

\section{Comparison of general clinical data between two groups}

Gender and age distribution, hypertension and smoker ratios, lipids, and glycated hemoglobin levels showed no significant difference between the two groups $(P>0.05$; Table 1).

Table 1. General clinical data of patients in the study.
\begin{tabular}{lccccccccc}
\hline Groups & $\mathrm{N}$ & $\begin{array}{c}\text { Gender } \\
(\mathrm{M} / \mathrm{F})\end{array}$ & $\begin{array}{c}\text { Ages } \\
(\text { Years })\end{array}$ & $\begin{array}{c}\text { Smoker } \\
(\mathrm{N})\end{array}$ & $\begin{array}{c}\text { Hypertension } \\
(\mathrm{N})\end{array}$ & $\begin{array}{c}\text { TC } \\
(\mathrm{mM})\end{array}$ & $\begin{array}{c}\text { TG } \\
(\mathrm{mM})\end{array}$ & $\begin{array}{c}\text { LDL-C } \\
(\mathrm{mM})\end{array}$ & $\begin{array}{c}\text { HbAlc } \\
(\mathrm{mM})\end{array}$ \\
\hline Control group & 108 & $65 / 43$ & $55.4 \pm 7.9$ & 43 & 52 & $5.54 \pm 1.07$ & $1.24 \pm 0.67$ & $2.74 \pm 0.54$ & $5.58 \pm 0.59$ \\
ACS group & 332 & $186 / 146$ & $57.4 \pm 9.0$ & 134 & 175 & $5.19 \pm 1.12$ & $1.32 \pm 0.47$ & $2.82 \pm 0.57$ & $5.91 \pm 0.77$ \\
P & $>0.05$ & $>0.05$ & $>0.05$ & $>0.05$ & $>0.05$ & $>0.05$ & $>0.05$ & $>0.05$ \\
\hline
\end{tabular}
TC = total cholesterol; TG = triglycerides; LDLC = low-density lipoprotein cholesterol; HbAIC = glycosylated
hemoglobin.

\section{Plasma NT-proBNP levels in patients of the two groups}

There was a statistically significant difference in NT-proBNP levels between the patients in the two groups $(\mathrm{P}<0.01)$, where the NT-proBNP levels in the control group were significantly lower than those in the ACS group as shown in Table 2.

\begin{tabular}{lccc}
\multicolumn{4}{l}{ Table 2. NT-proBNP levels between the two groups. } \\
\hline Groups & $\mathrm{N}$ & NT-proBNP & P \\
\hline Control group & 108 & $67.87 \pm 24.55$ & $<0.001$ \\
ACS group & 332 & $598.43 \pm 243.54$ & \\
\hline
\end{tabular}

$\mathrm{ACS}=$ acute coronary syndrome.

\section{DISCUSSION}

The present study found that the plasma NT-proBNP levels were significantly higher when ACS occurred, so plasma NT-proBNP may contribute to the early diagnosis of ACS. Related studies have also shown that inflammation-related biomarkers such as hs-CRP (Hong et al., 2011; Zhang et al. 2012), MMPs (Guzel et al., 2013; Zayani et al., 2013) and IL-6 (Sarrafzadegan et al., 2012) also have some predictive value in ACS and other cardiovascular events. However, at present, CK-MB and troponin were still commonly used in clinical ACS diagnosis, and it was not possible to achieve an early diagnosis of ACS. NT-proBNP is derived from precursor brain natriuretic peptide (proBNP) when it is cleaved to brain natriuretic peptide (BNP), and it is now widely used in cardiovascular clinical practice. NT-proBNP levels are closely related to the severity of heart failure and have become objective indicators in the diagnosis of heart failure and dyspnea. It has also been used in evaluating the effect of heart 
failure treatment (Cabassi et al., 2013). Recent studies found that the NT-ProBNP has a potential diagnostic value in myocardial ischemia. Elevated NT-proBNP levels can be observed in various stages of coronary heart disease (Ahluwalia et al., 2013; Ayhan et al., 2013). Galvani et al. (2004) found that the NT-proBNP had a predictive performance similar to BNP in acute myocardial infarction on admission and during hospitalization. In addition, NT-proBNP also has a potential value in end point prediction after acute cardiovascular events. Consistent with similar studies abroad, the present study found that NT-proBNP was significantly higher in patients in the ACS group. The determination of the indicator may contribute to the early diagnosis of ACS.

\title{
ACKNOWLEDGMENTS
}

\author{
Research supported by Natural Science Foundation of Xinjiang (\#2012A070).
}

\section{REFERENCES}

Ahluwalia N, Blacher J, Szabo de EF, Faure P, et al. (2013). Prognostic value of multiple emerging biomarkers in cardiovascular risk prediction in patients with stable cardiovascular disease. Atherosclerosis 228: 478-484.

Ayhan E, Isik T, Uyarel H, Ergelen M, et al. (2013). The impact of NT-proBNP on admission for early risk stratification of patients undergoing primary percutaneous coronary intervention. Kardiol. Pol. 71: 165-175.

Cabassi A, de Champlain J, Maggiore U, Parenti E, et al. (2013). Prealbumin improves death risk prediction of BNP-added Seattle Heart Failure Model: results from a pilot study in elderly chronic heart failure patients. Int. J. Cardiol. 168: 3334-3339.

Galvani M, Ottani F, Oltrona L, Ardissino D, et al. (2004). N-terminal pro-brain natriuretic peptide on admission has prognostic value across the whole spectrum of acute coronary syndromes. Circulation 110: 128-134.

Gravning J, Smedsrud MK, Omland T, Eek C, et al. (2013). Sensitive troponin assays and N-terminal pro-B-type natriuretic peptide in acute coronary syndrome: prediction of significant coronary lesions and long-term prognosis. Am. Heart J. 165: 716-724.

Guzel S, Serin O, Guzel EC, Buyuk B, et al. (2013). Interleukin-33, matrix metalloproteinase-9, and tissue inhibitor [corrected] of matrix metalloproteinase-1 in myocardial infarction. Korean J. Intern. Med. 28: 165-173.

Holm J, Vidlund M, Vanky F, Friberg O, et al. (2013). Preoperative NT-proBNP independently predicts outcome in patients with acute coronary syndrome undergoing CABG. Scand. Cardiovasc. J. Suppl. 47: 28-35.

Hong YJ, Jeong MH, Choi YH, Cho SH, et al. (2011). Relation between high-sensitivity C-reactive protein and coronary plaque components in patients with acute coronary syndrome: virtual histology-intravascular ultrasound analysis. Korean Circ. J. 41: 440-446.

Sarrafzadegan N, Sadeghi M, Ghaffarpasand F, Alisaeidi A, et al. (2012). Interleukin-6 and E-selectin in acute coronary syndromes and stable angina pectoris. A comparative study. Herz 37: 926-930.

Wlazel RN, Rysz J and Paradowski M (2013). Examination of serum pregnancy-associated plasma protein A clinical value in acute coronary syndrome prediction and monitoring. Arch. Med. Sci. 9: 14-20.

Zayani Y, Allal-Elasmi M, Jacob MP, Zidi W, et al. (2013). Peripheral blood levels of matrix and inflammatory mediators are elevated in Tunisian patients with acute coronary syndromes. Clin. Lab. 59: 169-175.

Zhang YC, Wei JJ, Wang F, Chen MT, et al. (2012). Elevated levels of oxidized low-density lipoprotein correlate positively with C-reactive protein in patients with acute coronary syndrome. Cell Biochem. Biophys. 62: 365-372. 